\title{
Inflammatory Response and Barrier Dysfunction by Different e-Cigarette Flavoring Chemicals Identified by Gas Chromatography-Mass Spectrometry in e-Liquids and e-Vapors on Human Lung Epithelial Cells and Fibroblasts
}

\author{
Janice Gerloff, ${ }^{1,}{ }^{\star}$ Isaac K. Sundar, ${ }^{1, *}$ Robert Freter, ${ }^{1}$ Emily R. Sekera, ${ }^{2}$ Alan E. Friedman, \\ Risa Robinson, Todd Pagano, and Irfan Rahman ${ }^{1}$
}

\begin{abstract}
Recent studies suggest that electronic cigarette (e-cig) flavors can be harmful to lung tissue by imposing oxidative stress and inflammatory responses. The potential inflammatory response by lung epithelial cells and fibroblasts exposed to e-cig flavoring chemicals in addition to other risk-anticipated flavor enhancers inhaled by e-cig users is not known. The goal of this study was to evaluate the release of the proinflammatory cytokine (interleukin-8 [IL-8]) and epithelial barrier function in response to different e-cig flavoring chemicals identified in various e-cig e-liquid flavorings and vapors by chemical characterization using gas chromatography-mass spectrometry analysis. Flavorings, such as acetoin (butter), diacetyl, pentanedione, maltol (malt), ortho-vanillin (vanilla), coumarin, and cinnamaldehyde in comparison with tumor necrosis factor alpha (TNF $\alpha$ ), were used in this study. Human bronchial epithelial cells (Beas2B), human mucoepidermoid carcinoma epithelial cells (H292), and human lung fibroblasts (HFL-1) were treated with each flavoring chemical for 24 hours. The cells and conditioned media were then collected and analyzed for toxicity (viability \%), lung epithelial barrier function, and proinflammatory cytokine IL-8 release. Cell viability was not significantly affected by any of the flavoring chemicals tested at a concentration of $10 \mu \mathrm{M}$ to $1 \mathrm{mM}$. Acetoin and diacetyl treatment induced IL-8 release in Beas2B cells. Acetoin- and pentanedione-treated HFL-1 cells produced a differential, but significant response for IL- 8 release compared to controls and TNF $\alpha$. Flavorings, such as ortho-vanillin and maltol, induced IL-8 release in Beas2B cells, but not in H292 cells. Of all the flavoring chemicals tested, acetoin and maltol were more potent inducers of IL- 8 release than TNF $\alpha$ in Beas2B and HFL-1 cells. Flavoring chemicals rapidly impaired epithelial barrier function in human bronchial epithelial cells (16-HBE) as measured by electric cell surface impedance sensing. Our findings suggest that some of the e-cig liquids/aerosols containing flavoring chemicals can cause significant loss of epithelial barrier function and proinflammatory response in lung cells.
\end{abstract}

Keywords: barrier function, diacetyl, electronic cigarettes, flavors, inflammation, interleukin-8

Introduction

$\mathbf{E}$ Lectronic Cigarettes or "e-cigs" are nicotinedelivering devices that are powered by a battery and use an atomizer to heat the liquid flavor. These electronic nicotine delivery system (ENDS) devices have become popular among teens and young adults due to the alluring different types of flavorings offered, which are used as additives. ${ }^{1-3}$ The National Health information survey revealed that $3.7 \%$ of adults are users of e-cigs. ${ }^{4}$ Flavored e-cigs are a public health

\footnotetext{
${ }^{1}$ Department of Environmental Medicine, University of Rochester Medical Center, Rochester, New York.

${ }^{2}$ Department of Chemistry, University of Buffalo, Buffalo, New York.

Departments of ${ }^{3}$ Mechanical Engineering and ${ }^{4}$ Science \& Mathematics, Rochester Institute of Technology/National Technical Institute for the Deaf, Rochester, New York.

*The first two authors contributed equally to this article.

(C) Janice Gerloff et al., 2017; Published by Mary Ann Liebert, Inc. This Open Access article is distributed under the terms of the Creative Commons Attribution Noncommercial License (http://creativecommons.org/licenses/by-nc/4.0/), which permits any noncommercial use, distribution, and reproduction in any medium, provided the original author(s) and the source are credited.
} 
concern not just because they attract youth for experimentation (gateway for initiating tobacco products) but also due to the presence of chemicals that serve as flavorings that may lead to their own health hazards. ${ }^{5}$ Flavoring chemicals contain harmful aerosol constituents, such as maltol, vanillin, acetoin, and diacetyl apart from nicotine, vegetable glycerin, and propylene glycol/glycerol. ${ }^{6-11}$

There are about 466 distinct brands of e-cig products and more than 8000 flavors for e-cigs on the market. ${ }^{12}$ Recent studies have shown that cytotoxic effects posed by e-liquids are mainly due to increasing the concentrations of the flavoring agents. ${ }^{5,10,13-15}$ E-juice, a popular brand offers a variety of flavored e-liquids such as chocolate, vanilla, menthol, cinnamon, grape, apple, strawberry, mango, cotton candy, and coffee. These flavors are certified as safe for ingestion by the Flavor Extracts Manufacturers Association (FEMA). However, concerns have been raised about the potential inhalation toxicity of these favoring chemicals. ${ }^{1,10}$ Diacetyl is a known chemical that can cause bronchiolitis obliterans (popcorn lung). ${ }^{5,16}$ Bronchiolitis obliterans is inflammation of the bronchioles due to inhalation of chemical particles. ${ }^{16}$

The inflammation can cause irreversible scarring that can damage lung fibroblasts and epithelial cells. Diacetyl or other e-cig flavoring chemicals enter the body when a person inhales e-cig aerosols, affecting both the oral and respiratory systems. The proinflammatory effect of these flavoring chemicals or aerosols on respiratory epithelium is not known. There is an urge for research on flavor additives used in e-cigs since there is a lack of safety data available on both the short- and long-term health effects and toxicity from inhaling flavoring chemicals.

The purpose of this study was to determine if flavoring chemicals in e-cigs/e-liquids can cause the release of proinflammatory cytokine, interleukin-8 (IL-8), in a variety of human lung epithelial cells (Beas2B and H292) and human lung fibroblasts (HFL-1) in vitro and barrier dysfunction in human bronchial epithelial cells (16-HBE). The airway epithelium forms the highly regulated barrier against inhaled noxious gases and vapors (e.g., cigarette smoke and inhaled nicotine). In response to various cellular stresses, this barrier function is affected, thereby allowing increased access of pollutants and pathogens (bacteria and viruses) to the submucosa, culminating in an inflammatory response.

Tight junctions (TJs) play an essential role in maintaining the epithelial barrier function along with other interacting proteins, such as occludin, zona occludens-1, and claudins. The TJs are critical for epithelial homeostasis and restrict paracellular permeability and provide a protective role by keeping the basolateral region separated from the apical region. ${ }^{17}$ The effects of e-cig flavorings on epithelial resistance as a readout for barrier function have not been investigated. We used a nontoxic concentration of nicotine and flavoring chemicals to evaluate the epithelial barrier function using 16-HBE cells in vitro.

We used a Cellometer to determine the cell viability before and after treatment with various flavoring chemicals. A standard enzyme-linked immunosorbent assay (ELISA) was used to determine the secretion of the IL-8 cytokines from both epithelial cells and fibroblasts in response to various flavoring agents. Three different concentrations of flavoring chemicals were identified in various e-liquids to define the dose-response effects on proinflammatory media- tor release. Various flavoring chemicals tested in this study include the following: acetoin (butter), diacetyl, pentanedione, maltol (malt), ortho-vanillin (vanilla), coumarin, and cinnamaldehyde. Tumor necrosis factor alpha $(\mathrm{TNF} \alpha)$ was used as positive control, and an appropriate culture medium with $1 \%$ fetal bovine serum (FBS) was included as control (nontreatment control) to determine the levels of IL-8 release from human lung epithelial cells and fibroblasts 24 hours after treatment.

\section{Materials and Methods}

\section{Scientific rigor}

We used a rigorous/robust and unbiased approach throughout the experimental plans and during the analysis of the results so as to ensure that our data are reproducible along with detailed reporting of both methods and raw/analyzed data.

\section{Flavored e-cig e-liquids/e-juices}

E-cig flavor solutions (e-liquid) with and without nicotine were acquired from a retail smoke shop in Rochester, NY, for purposes of assessing the general composition of flavored eliquids. Various flavored e-liquids/e-juices such as Classic Tobacco (0 and $24 \mathrm{mg}$ nicotine), Cinnamon Roll (0 mg nicotine), Cotton Candy ( $0 \mathrm{mg}$ nicotine), Grape Vape (0 mg nicotine), Strawberry Fields (0 mg nicotine), and Strawberry Zing (0 mg nicotine) were obtained from Vape Dudes, Gourmet e-juice. Café Cubano (18 mg nicotine), Clove (18 mg nicotine), Coffee (18 mg nicotine), Havana Cigar (18 mg nicotine), and Mountain Du Voltage (18 mg nicotine) were obtained from Upstate Vape (Rochester NY). Melon Mania (0 mg nicotine) and Peaches and Cream (0 mg nicotine) were obtained from Drip e-liquid.

Four other flavored e-liquids were also acquired from a retail smoke shop in Rochester, NY: cinnamon, menthol, and mango containing $24 \mathrm{mg}$ nicotine (White Rhino), and vanilla containing $1.8 \%$ nicotine (Crown Seven). These four common flavored e-liquids were selected for the direct comparison of e-liquid and emission-derived vapor chemical analyses.

\section{Gas chromatography-mass spectrometry survey and assessment of flavored e-liquid composition}

E-liquids were injected after being diluted in methylene chloride 2:10 into the gas chromatography-mass spectrometry (GC-MS; Hewlett Packard 5890 series [GC] equipped with a Hewlett Packard 5972 series [MS] Mass Selective Detector). Helium was used as the carrier gas at a flow of $1.0 \mathrm{~mL} / \mathrm{min}$. The initial oven temperature was set to $60^{\circ} \mathrm{C}$ with an initial 4.0-minute hold followed by a programmed temperature ramp of $25^{\circ} \mathrm{C} / \mathrm{min}$ until a final temperature of $285^{\circ} \mathrm{C}$ was reached and held for 5 minutes. The total analysis time for each sample was 18 minutes. The instrument was equipped with a $\mathrm{J} \& W$ Scientific, Inc. column $(30 \mathrm{~m} \times 0.250 \mathrm{~mm})$ with a $0.10 \mu \mathrm{m}$ thin film of phenyl arylene polymer (Catalog No. 122-5531). The samples were analyzed over the range of $50-550 \mathrm{~m} / \mathrm{z}$ at 1.5 scans per second using electron-impact ionization in the positive ion mode. Using the program MS Chemstation (Hewlett Packard), data from each chromatogram obtained from the solutions were compared to known compounds using the Wiley Database incorporated with the program. 


\section{Generation and capture of e-cig emissions}

Each of the four selected flavored e-liquids (menthol, cinnamon, mango, and vanilla) were vaped with an iTaste MVP 2.0 controller equipped with an iClear X.I tank, both manufactured by Innokin. The e-cig controller was set to $7.5 \mathrm{~W}$, and the coil had an indicated resistance of $2.1 \Omega$. To prevent cross-flavor contamination resulting from residual e-liquid in the coil/wick assembly, each flavored solution was vaped with a new coil/wick assembly. The device tank body was thoroughly cleaned and dried with each flavor change. Emissions were generated on Rochester Institute of Technology's Programmable Emissions System (PES). The instrument utilizes an evacuated chamber to provide a suction source for puffing or vaping. A proportioning valve under the regulation of a PID (proportional, integral, derivative) algorithm controls the air flow rate through the e-cig with respect to a programmed puff profile. For these experiments, the puff profile or topography consisted of 3.5-second duration puffs at an air flow rate of $33.8 \mathrm{~mL} / \mathrm{s}$, based on topography measurements from the natural environment.

Emissions were captured on $48 \mathrm{~mm}$ silica filter pads (Performance Systematix, Inc.). The filter pads were contained within a Cambridge style filter holder located in the air flow path between the e-cig and the PES input port. For each e-liquid flavor, 10 filter pads were exposed to 10 puffs each, for a total of 100 puffs collected for each e-liquid. Each filter pad was stored in separate and sealed brown glass sampling jars before GC-MS analysis.

\section{Qualitative analysis of flavoring components in selected e-liquids and emission/vapors}

The filter pads that were loaded with emissions from the PES were prepared for analysis by GC-MS. The 10 filter pads collected for each flavored e-cig were combined to increase the analytical signal. Fifty milliliters of methanol (HPLC grade; Fisher Scientific) was added to each set of loaded filter pads and placed on an orbital shaker (200 rpm) for about 24 hours. To completely break down the filter pads, a wrist action shaker was next used to shake the sample for 15 minutes, and then, the sample was again placed on the orbital shaker for another 24 hours. Resulting solutions were passed through $0.45 \mu \mathrm{m}$ regenerated cellulose filters into a graduated concentrator where they were concentrated by solvent blow-off to about 30 times the initial concentration. This solution was transferred into a GC sample vial containing a $200 \mu \mathrm{L}$ insert for small volumes.

E-liquids for each of the same four selected flavored samples were also prepared for qualitative analysis by GC-MS. Twenty-five microliters of each e-liquid was diluted with $975 \mu \mathrm{L}$ of methanol (HPLC grade; Fisher Scientific) and placed into GC sample vials. One microliter of each e-liquid and emission sample was sequentially injected into the split injector (25:1 split) of a Shimadzu QP2020 GC-MS (run in the electron ionization mode). Helium was used as the carrier gas and a constant flow rate of $1.00 \mathrm{~mL} / \mathrm{min}$ was supplied to a $30 \mathrm{~m} \times 0.250 \mathrm{~mm} \times 0.25 \mu \mathrm{m}$ DB-17MS capillary column (Agilent, Santa Clara, CA). The GC-MS method was optimized for our setup from the method of Hutzler et al. ${ }^{7}$ The column was heated at $10^{\circ} \mathrm{C} / \mathrm{min}$ from $40^{\circ} \mathrm{C}$ to $170^{\circ} \mathrm{C}$ where the temperature was held for 2 minutes, then increased at $8^{\circ} \mathrm{C} / \mathrm{min}$ to $250^{\circ} \mathrm{C}$, and finally heated at $25^{\circ} \mathrm{C} / \mathrm{min}$ to $320^{\circ} \mathrm{C}$, where it was held for 5 minutes. The total run-time was about 33 minutes for each injection. The ion source for the MS was held at $200^{\circ} \mathrm{C}$, while the transfer was kept at $280^{\circ} \mathrm{C}$. The 2014 NIST mass spectral database was used for the identification of chromatographic peaks.

\section{Cell culture}

Human bronchial epithelial cells (Beas2B; ATCC, Manassas, VA), human mucoepidermoid carcinoma epithelial cells (H292; ATCC), and human primary lung fibroblasts (HFL-1; ATCC) were cultured at $37^{\circ} \mathrm{C}$ in a suitable culture medium. Briefly, Beas2B cells were grown in the DMEMHam's F12 50:50 mixture (DMEM-F12; Mediatech, Manassas, VA) supplemented with 5\% FBS, $15 \mathrm{mM}$ HEPES, penicillin $(100 \mathrm{U} / \mathrm{mL})$, and streptomycin $(100 \mu \mathrm{g} / \mathrm{mL})$. H292 cells were grown in RPMI-1640 supplemented with $10 \%$ FBS, 2 mM L-glutamine, penicillin $(100 \mathrm{U} / \mathrm{mL})$, and streptomycin $(100 \mu \mathrm{g} / \mathrm{mL})$. HFL-1 cells were grown in Dulbecco's modified Eagle's medium (DMEM) supplemented with $10 \%$ FBS, $1 \times$ MEM nonessential amino acids, $2 \mathrm{mM}$ L-glutamine, penicillin $(100 \mathrm{U} / \mathrm{mL})$, and streptomycin $(100 \mu \mathrm{g} / \mathrm{mL})$. Before treatment with flavoring chemicals, cells were cultured to $85 \%-90 \%$ confluence under $5.0 \% \mathrm{CO}_{2}$ in six-well plates.

16-HBE cells (ATCC), an immortalized normal bronchial epithelial cell line, were kindly provided by Dr. Steve N. Georas (Department of Medicine, Pulmonary Diseases and Critical Care, University of Rochester Medical Center, Rochester, NY). 16-HBE cells were cultured in DMEM containing $4.5 \mathrm{~g} / \mathrm{L}$ glucose, L-glutamine, and sodium pyruvate (Mediatech, Manassas, VA) supplemented with 10\% FBS, penicillin $(100 \mathrm{U} / \mathrm{mL})$, streptomycin $(100 \mu \mathrm{g} / \mathrm{mL})$, amphotericin B $(250 \mu \mathrm{g} / \mathrm{mL})$, and HEPES $(15 \mathrm{mM})$.

\section{Flavoring chemicals and cell treatments by different flavoring agents}

Epithelial cells and fibroblasts were treated with flavoring chemicals such as acetoin (butter), diacetyl, pentanedione, maltol (malt), ortho-vanillin (vanilla), coumarin, and cinnamaldehyde (analytical grade $>95 \%$ pure; Sigma). TNF $\alpha$ was used as positive control and untreated cells were used as controls. For flavoring chemical treatment, Beas2B, H292, and HFL-1 cells were grown to $~ 85 \%-90 \%$ confluence. Cells were serum starved overnight in a suitable culture medium supplemented with low FBS $(0.5 \%)$ and treated with appropriate flavoring chemicals (concentrations: $10 \mu \mathrm{M}$, $100 \mu \mathrm{M}$, and $1 \mathrm{mM})$ or (TNF $\alpha 10 \mathrm{ng} / \mathrm{mL}$, positive control) for 24 hours at $37^{\circ} \mathrm{C}$ with $5 \% \mathrm{CO}_{2}$.

16-HBE cells were initially seeded in electric cell surface impedance sensing (ECIS) cultureware (8W10E+ PET) at a density of $1.75 \times 10^{5}$ cells/well containing $400 \mu \mathrm{L}$ complete medium (10\% FBS). After 24-48 hours, low serum containing media ( $1 \%$ FBS) were added, a few hours later the cells were treated with different flavoring chemicals $(1 \mathrm{mM})$ in batches. All the treatments were performed in separate eight-well ECIS cultureware, and nicotine (1 mM) was used as positive control. Transepithelial resistance (TEER) data were collected in real time pre- and post-treatment (15 hours) using ECIS Z $\theta$ 16-well array station (Applied Biophysics, Troy, NY). 


\section{Cellometer}

Using the acridine orange (AO) and propidium iodide (PI) staining, viability was determined in Beas2B, H292, and HFL-1 cells for plating and after treatment with flavoring chemicals. AO/PI staining and viability determination were performed in $20 \mu \mathrm{L}$ of live cells combined with $20 \mu \mathrm{L}$ of AO/PI staining solution. Finally, $20 \mu \mathrm{L}$ of stained cells were then added to a Cellometer counting chamber and analyzed using a fluorescent Cellometer. At the end of the analysis, the Cellometer automatically reports live and/or dead cell number, live and/ or dead cell concentration, mean diameter, and percent viability in terms of cell toxicity to flavoring chemicals 24 hours after treatment.

\section{Enzyme-linked immunosorbent assay}

Following cell treatments, conditioned media were collected 24 hours post-treatment of different concentrations of flavoring chemicals. Proinflammatory cytokine (IL-8) release was determined using the IL-8 cytoset ELISA kit according to the manufacturer's instructions (Life Technologies). Each specified cell type (Beas2B, HFL-1, and H292) had its own untreated control and $\mathrm{TNF} \alpha$-positive control groups, which were used as a basis of comparison when analyzing IL-8 levels shown in Figures 1-3.

\section{Electric cell surface impedance sensing}

To assess the effects of different flavoring chemicals on epithelial barrier function, we measured electrical resistance in a confluent monolayer of 16-HBE cells using the ECIS system (Applied Biophysics) as previously described. ${ }^{18}$ In brief, resistance was measured using the multiple frequency mode and calculated using $4000 \mathrm{~Hz}$ frequency for all the different treatment conditions.

\section{Statistical analysis}

Statistical analysis of significance was analyzed by one-way ANOVA (Tukey's multiple comparison test) for IL-8 ELISA and two-way ANOVA (Sidak's multiple comparisons test) for ECIS data using GraphPad Prism 6 (La Jolla, CA). Probability of significance compared to control for more than two treatment groups (control vs. different concentrations of same flavoring chemicals; and control vs. different flavoring chemicals). Data are presented as mean \pm standard error of the mean. $p<0.05$ is considered as statistically significant.

\section{Results}

\section{Components identified in survey and assessment} of flavored e-liquids by GC-MS

Using GC-MS analysis for the e-cig liquids, we found several chemicals in various flavoring liquids containing
A

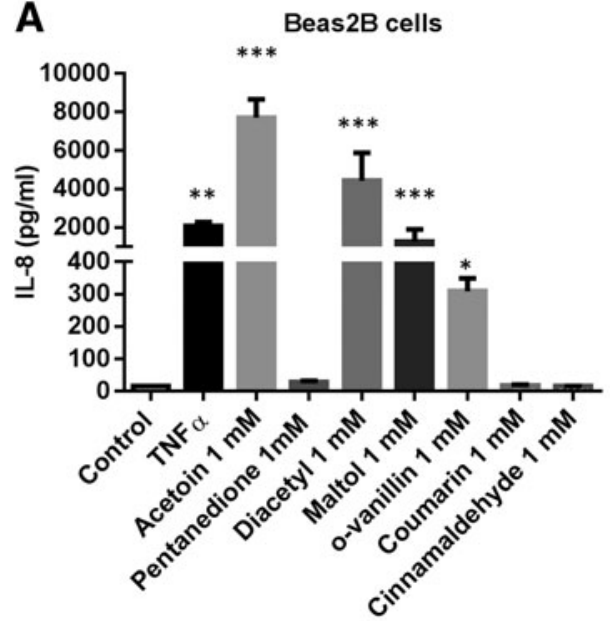

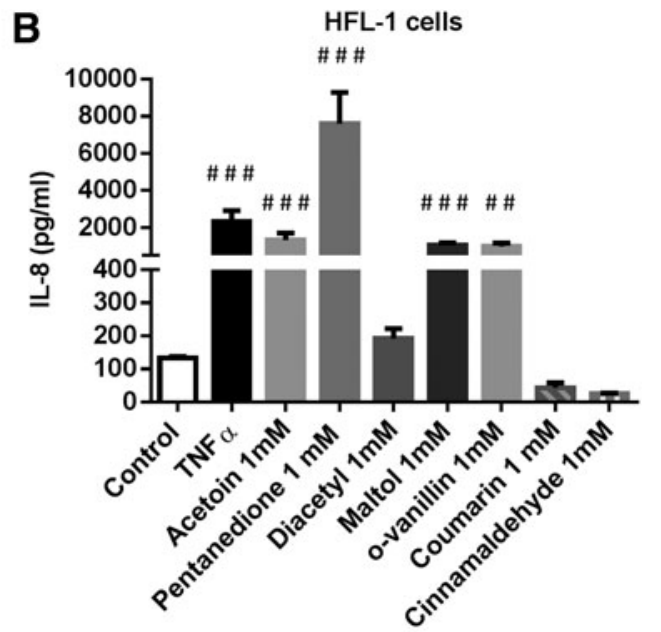

H292 cells

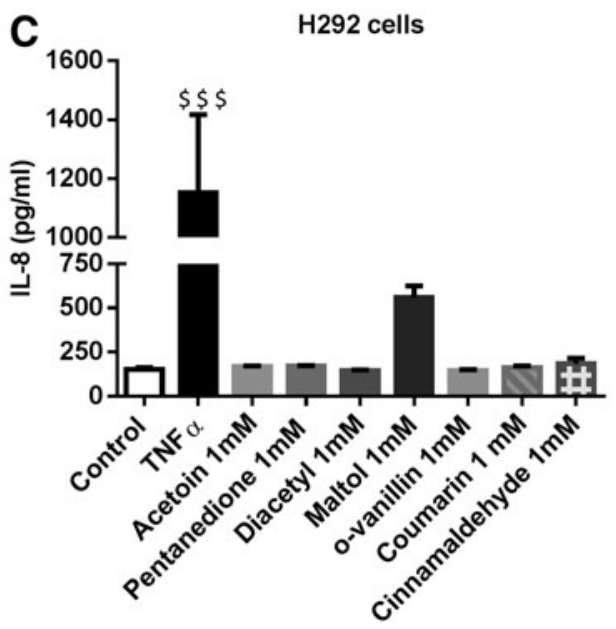

FIG. 1. Comparative and differential effects of e-cig flavoring chemicals induced proinflammatory response in human lung epithelial cells and fibroblasts. Human bronchial epithelial cells

(Beas2B), human lung fibroblasts (HFL-1), and human transformed lung epithelial cells (H292) were treated with different flavoring chemicals at $1 \mathrm{mM}$ concentration and then incubated at $37^{\circ} \mathrm{C}$ and $5 \% \mathrm{CO}_{2}$ for 24 hours. Levels of IL-8 release in culture media were determined by ELISA from control (untreated) and different flavoring chemicaltreated (A) Beas2B, (B) HFL1, and (C) H292 cells. Data are expressed as mean \pm SEM ( $n=3$ /group), and significance determined using oneway ANOVA (Tukey's multiple comparisons test). $* p<0.05, * * p<0.01$, $* * * p<0.001,{ }_{\text {\#\# }} p<0.01$, \#\#\# $p<0.001, \$ \$ \$ p<0.001$ versus untreated control Beas2B or HFL-1 or H292. e-cig, electronic cigarette; ELISA, enzyme-linked immunosorbent assay; IL-8, interleukin-8; SEM, standard error of the mean. 
FIG. 2. E-cig flavorings acetoin, pentanedione, and diacetyl caused dose-

dependent proinflammatory response in human lung epithelial cells and fibroblasts. Human bronchial epithelial cells (Beas2B), human lung fibroblasts (HFL-1), and human transformed lung epithelial cells (H292) were treated with different doses of flavoring chemicals $(10 \mu \mathrm{M}$, $100 \mu \mathrm{M}$, and $1 \mathrm{mM}$ ) and then incubated at $37^{\circ} \mathrm{C}$ and $5 \%$ $\mathrm{CO}_{2}$ for 24 hours. Levels of IL-8 release in culture media were determined by ELISA from control (untreated) and (A) acetoin-, (B) pentanedione-, and (C) diacetyl-treated Beas2B, HFL-1, and H292 cells. Data are expressed as mean \pm SEM ( $n=3$ /group), and significance determined using one-way ANOVA (Tukey's multiple comparisons test). $* p<0.05$, $* * p<0.01, * * * p<0.001$, $\# p<0.01, \# \# p<0.001$, $\$ \$ p<0.001$ versus untreated control Beas2B or HFL-1 or H292.

FIG. 3. E-cig flavorings ortho-vanillin, maltol, cinnamaldehyde, and coumarin caused dose-dependent proinflammatory response in human lung epithelial cells and fibroblasts. Human bronchial epithelial cells

(Beas2B), human lung fibroblasts (HFL-1) and human transformed lung epithelial cells (H292) were treated with different doses of flavoring chemicals $(10 \mu \mathrm{M}$, $100 \mu \mathrm{M}$, and $1 \mathrm{mM}$ ) and then incubated at $37^{\circ} \mathrm{C}$ and $5 \%$ $\mathrm{CO}_{2}$ for 24 hours. Levels of IL-8 release in culture media were determined by ELISA from control (untreated) and (A) ortho-vanillin-, (B) maltol-, (C) cinnamaldehyde-, and (D) coumarin-treated Beas2B, HFL-1, and H292 cells. Data are expressed as mean \pm SEM ( $n=3$ /group), and significance determined using one-way ANOVA (Tukey's multiple comparisons test). ${ }^{*} p<0.05$,

$* * p<0.01$ *** $p<0.001$; ${ }^{\#} p<0.05,{ }^{\#} p_{\$ \$ \$} 0.01$, $p<0.001,{ }^{\$ \$ \$} p<0.001$ versus untreated control Beas2B or HFL-1 or H292.
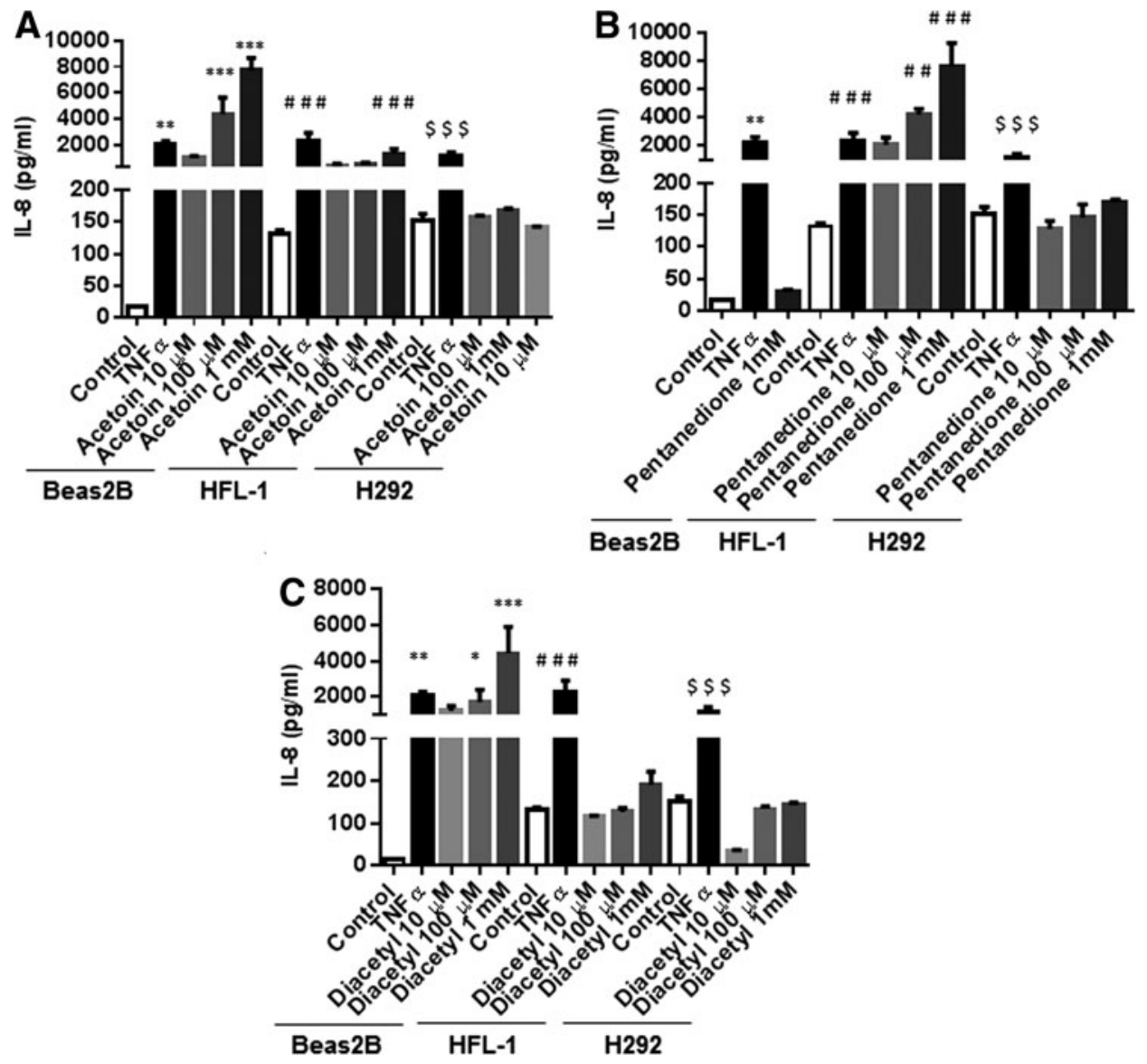

A
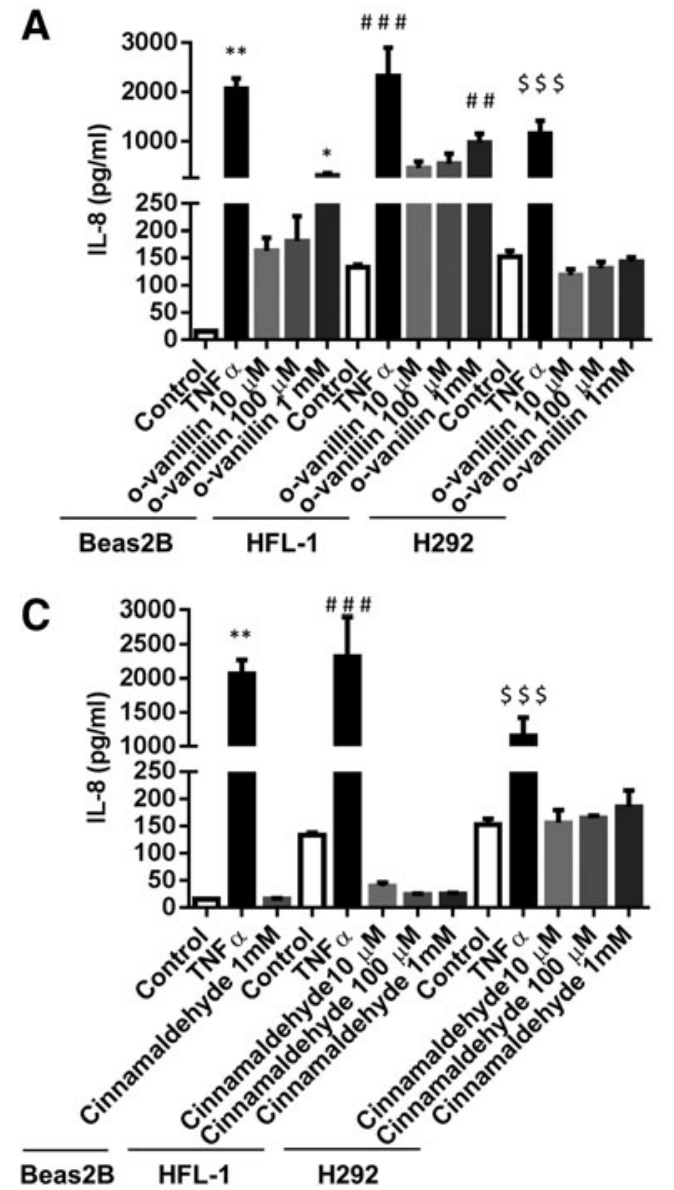
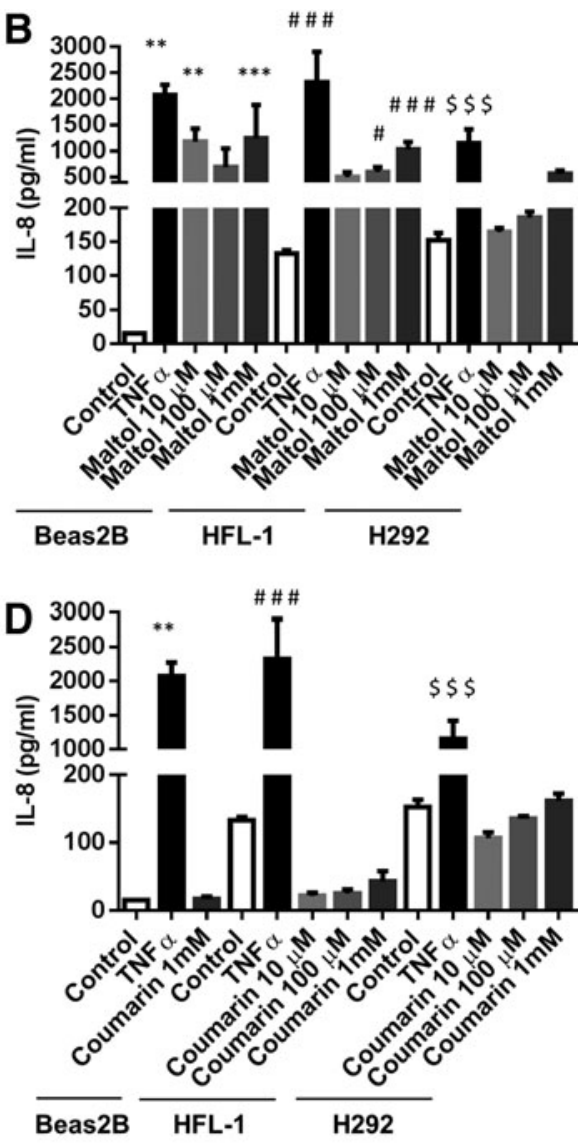
0-24 mg nicotine. Only the chemicals identified based on GC-MS data that had a quality score $>50$ were summarized in the table (Table 1). We used some of the key flavoring chemicals, such as vanillin, cinnamon-derived chemicals, and maltol, as well as the other chemicals identified previously ${ }^{5}$ for cell treatments.

\section{Flavoring chemicals identified in select e-liquids and their emissions/vapors by GC-MS}

Using four selected flavored e-liquids, menthol, cinnamon, mango (24 mg nicotine), and vanilla (1.8\% nicotine), among other flavor-related components, we also found vanillin, maltol, and cinnamon-derived chemicals (Table 2), which affirms some of the observations from other e-liquids listed in Table 1.

After identification of some analytes of interest in flavored e-liquid samples, we began to investigate the corresponding puffed samples that had been puffed through our puffing machine onto Cambridge filter pads, also using the optimized GC-MS method. The resulting chromatograms from the emission pad samples were analyzed using the mass spectra and NIST database to identify the molecules present in the emissions/vapors of the flavored e-liquid products. These results are also shown in Table 2. We were able to identify cinnamaldehyde and vanillin and their derivatives, ethyl maltol, benzaldehyde, pyrazine, menthol, and other chemicals. However, the filter pad method may be limited in the ability to fully capture volatile chemicals. Some of the identified chemicals were used in our subsequent cell culture studies.

\section{E-cig flavoring chemicals increase $I L-8$ release in Beas2B and HFL-1 cells without any effect on $\mathrm{H} 292$ cells}

We tested some of the identified chemicals from our GC-MS data, acetoin (butter), pentanedione, diacetyl, and other flavoring chemicals (maltol, ortho-vanillin, coumarin, and cinnamaldehyde), to determine whether they will cause a proinflammatory response in lung epithelial cells and fibroblasts. Untreated cells were used as negative controls and $\mathrm{TNF} \alpha(10 \mathrm{ng} / \mathrm{mL})$ was used as a positive control. We found that flavoring chemicals, acetoin, diacetyl, maltol, and ortho-vanillin, were able to significantly induce IL-8 release in Beas2B cells at $1 \mathrm{mM}$ concentration (Fig. 1A). Similarly, HFL-1 cells treated with acetoin, pentanedione, maltol, and orthovanillin at $1 \mathrm{mM}$ concentrations were able to induce IL-8 release compared to the untreated control group (Fig. 1B). However, these flavoring chemicals were unable to produce a significant proinflammatory response in transformed lung epithelial cells (H292) (Fig. 1C).

Acetoin treatment $(1 \mathrm{mM})$ in Beas2B cells showed a significant increase in IL- 8 release when compared to TNF $\alpha$ (positive control) (Fig. 1A). In HFL-1 cells, only pentanedione $(1 \mathrm{mM})$ showed a significant increase in IL-8 release when compared to $\mathrm{TNF} \alpha$. Of the seven different flavoring chemicals tested, two flavoring chemicals (cinnamaldehyde and coumarin) did not induce IL-8; instead, they caused suppression of IL-8 in Beas2B and HFL-1 cells. Overall, we see a cell-type-specific response to IL-8 secretion in Beas2B and HFL-1 cells treated with different flavoring chemicals (Table 3).

\section{E-cig flavoring agents induce secretion of IL-8 from lung epithelial cells and fibroblasts in a dose-dependent manner}

We performed dose-response experiments using different flavoring chemicals in Beas2B, HFL-1, and H292 cells. Beas $2 \mathrm{~B}$ cells treated with acetoin $(100 \mu \mathrm{M}$ and $1 \mathrm{mM})$, diacetyl (100 $\mu \mathrm{M}$ and $1 \mathrm{mM})$, ortho-vanillin $(1 \mathrm{mM})$, and maltol $(10 \mu \mathrm{M}$ and $1 \mathrm{mM}$ ) show a significant increase in IL-8 release compared to the untreated control in a dose-dependent manner (Figs. 2A-C and 3A-D). Similarly, HFL-1 cells treated with acetoin $(1 \mathrm{mM})$, pentanedione $(100 \mu \mathrm{M}$ and $1 \mathrm{mM})$, orthovanillin $(1 \mathrm{mM})$, and maltol $(100 \mu \mathrm{M}$ and $1 \mathrm{mM})$ show a significant increase in IL-8 release compared to the untreated control in a dose-dependent manner (Figs. 2A-C and 3A-D). The extent of increased IL-8 release was differential and more pronounced in Beas2B (acetoin, diacetyl, ortho-vanillin, and maltol) and HFL-1 cells (acetoin, pentanedione, ortho-vanillin, and maltol). These flavoring chemicals were unable to produce a significant proinflammatory response dose-dependently in transformed lung epithelial cells (H292) (Figs. 2A-C and $3 \mathrm{~A}-\mathrm{D})$. Cell viability was not affected in any of the cell and treatment groups as it remained $\sim 80 \%-85 \%$ post-treatments. No significant cytotoxicity was seen by any of the flavoring chemicals at the tested concentrations.

\section{E-cig flavoring agents caused loss of epithelial barrier function in 16-HBE cells}

To determine the effect of e-cig flavoring chemicals on epithelial barrier function, we first compared the effect of nicotine (positive control) and different flavoring chemicals at a nontoxic concentration $(1 \mathrm{mM})$ in a monolayer of $16-\mathrm{HBE}$ cells. Representative absolute resistance values for nicotine and different flavoring chemicals simultaneously show epithelial barrier dysfunction in 16-HBE cells (Fig. 4A). The addition of nicotine $(1 \mathrm{mM})$ exhibited rapid and transient loss of epithelial barrier function reflected by a maximum decrease in normalized resistance at 20 minutes post-treatment (Fig. 4B).

Similarly, treatments with different flavoring chemicals, such as diacetyl and coumarin, showed a decline in normalized resistance (TEER) at 20 minutes post-treatment (Fig. 4B). In contrast, pentanedione and ortho-vanillin showed less effect with no loss of barrier function at 20 minutes post-treatment (Fig. 4B). When we analyzed TEER data at 2 hours posttreatment, 16-HBE cells treated with acetoin, maltol, and cinnamaldehyde compared to control showed significant and persistent loss of barrier function (Fig. 4C). Overall, these data suggest that e-cig containing nicotine and flavoring chemicals contributes to epithelial barrier dysfunction in human bronchial epithelial cells that may influence the proinflammatory responses in lung cells.

\section{Discussion}

The use of vape pens, e-hookahs, e-cigars, e-pipes, and other ENDS products has gained more popularity among both adolescents and young adults due to the availability of numerous flavored e-liquids/refills on the market today. The chemical characteristics and presence of potentially toxic chemicals in ENDS flavorings and the potential adverse respiratory toxicology effects due to exposure of flavoring aerosols/e-liquids remain largely unexplored. We have 


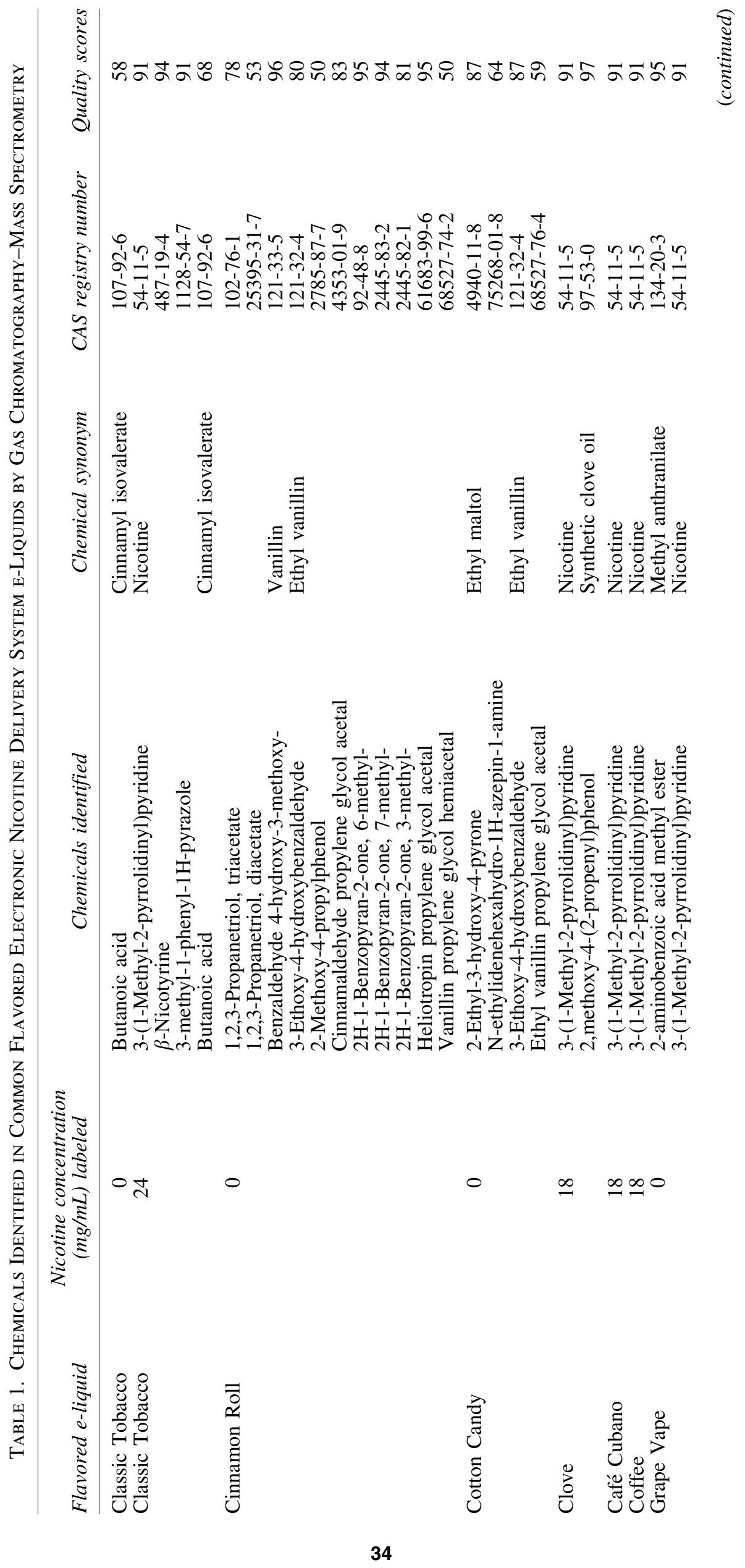




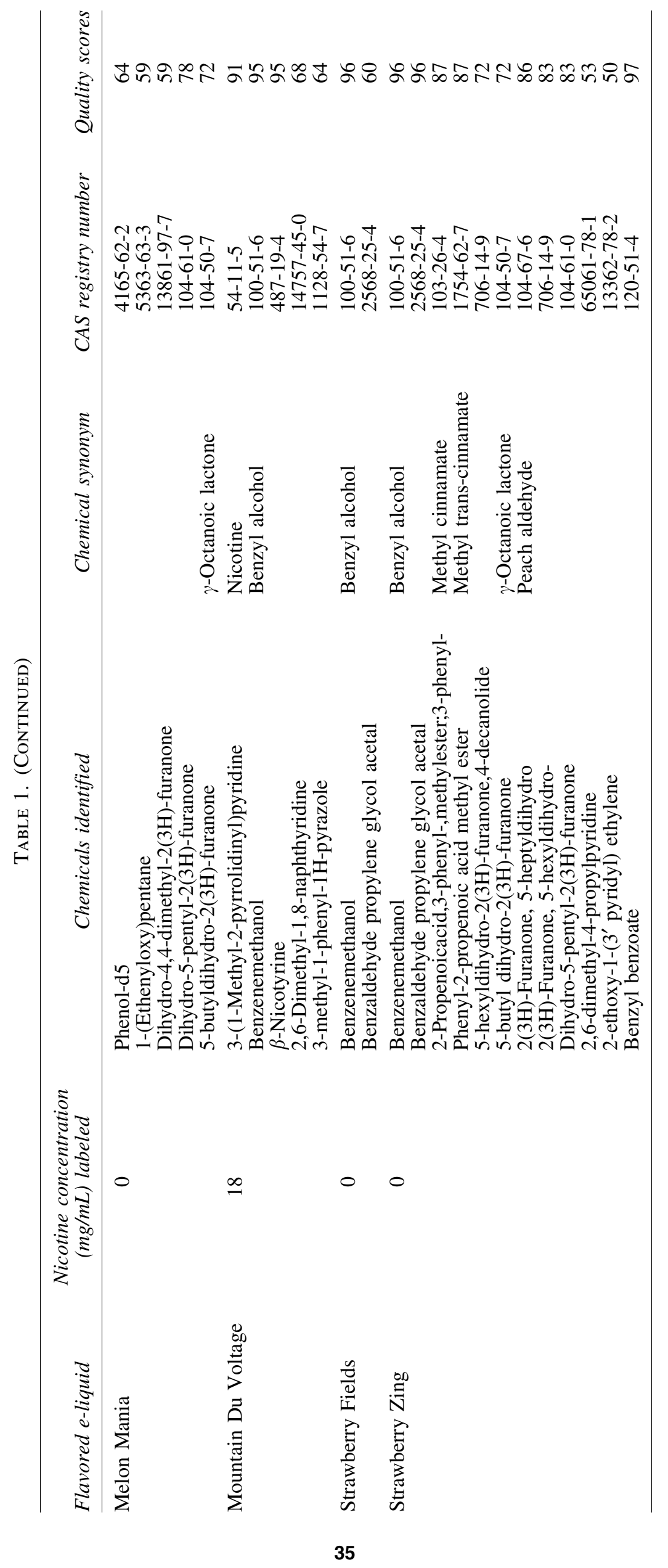


Table 2. Detection of Flavoring Chemicals in e-Liquids and Emissions of Flavored Electronic Nicotine Delivery System

\begin{tabular}{|c|c|c|c|c|c|}
\hline $\begin{array}{l}\text { Flavored } \\
\text { e-liquid }\end{array}$ & $\begin{array}{c}\text { Nicotine } \\
\text { concentration } \\
(m g / m L) \text { labeled }\end{array}$ & $\begin{array}{c}\text { Chemicals } \\
\text { identified by } \\
\text { GC-MS }\end{array}$ & Chemical identified & $\begin{array}{c}\text { CAS registry } \\
\text { number }\end{array}$ & $\begin{array}{c}\text { Mol. wt. } \\
\text { (g/mol) }\end{array}$ \\
\hline Cinnamon & $24 \mathrm{mg}$ & Emission & $\begin{array}{l}\text { Benzaldehyde } \\
\text { Cinnamaldehyde } \\
\text { Ethyl vanillin } \\
\text { Cinnamic acid, o-methoxy- } \\
\text { Methyl eugenol } \\
\text { Cinnamaldehyde } \\
\text { Ethyl vanillin }\end{array}$ & $\begin{array}{r}100-52-7 \\
104-55-2 \\
121-32-4 \\
6099-03-2 \\
93-15-2 \\
104-55-2 \\
121-32-4\end{array}$ & $\begin{array}{l}106 \\
132 \\
166 \\
178 \\
178 \\
132 \\
166\end{array}$ \\
\hline Mango & $24 \mathrm{mg}$ & Emission & $\begin{array}{l}\text { Hexanal propylene glycol acetal } \\
\delta \text {-Decalactone } \\
\gamma \text {-Decanolactone } \\
\text { Vanillin } \\
\beta \text {-Ionone } \\
\text { Hexyl caproate } \\
\text { Myosmine } \\
\text { Hexanal propylene glycol acetal } \\
\delta \text {-Decalactone } \\
\gamma \text {-Decanolactone }\end{array}$ & $\begin{array}{r}1599-49-1 \\
705-86-2 \\
706-14-9 \\
121-33-5 \\
14901-07-6 \\
6378-65-0 \\
512-12-7 \\
1599-49-1 \\
705-86-2 \\
706-14-9\end{array}$ & $\begin{array}{l}158 \\
170 \\
170 \\
152 \\
192 \\
200 \\
146 \\
158 \\
170 \\
170\end{array}$ \\
\hline Menthol & $24 \mathrm{mg}$ & E-liquid & $\begin{array}{l}\text { Pyrazine, 2,3,5-Trimethyl- } \\
\gamma \text {-Octalactone } \\
\text { dl-Menthol } \\
\delta \text {-Decalactone } \\
\text { Pyrazine, 2,3,5-trimethyl- } \\
\text { dl-Menthol } \\
\text { Carotol }\end{array}$ & $\begin{array}{r}14667-55-1 \\
104-50-7 \\
89-78-1 \\
705-86-2 \\
14667-55-1 \\
89-78-1 \\
465-28-1\end{array}$ & $\begin{array}{l}122 \\
142 \\
156 \\
170 \\
122 \\
156 \\
222\end{array}$ \\
\hline Vanilla & $1.8 \%$ & Emission & $\begin{array}{l}\text { Ethyl maltol } \\
\text { Piperonal } \\
\text { Vanillin } \\
\text { Isobutyl caproate } \\
\text { Vanillin, 2-methylpropyl ether } \\
\text { Piperonal propylene glycol acetal } \\
\text { Vanillin propylene glycol acetal } \\
\text { Ethyl maltol } \\
\text { Piperonal } \\
\text { Vanillin } \\
\text { Acetovanillin }\end{array}$ & $\begin{array}{r}4940-11-8 \\
120-57-0 \\
121-33-5 \\
105-79-3 \\
66488-79-7 \\
61683-99-6 \\
68527-74-2 \\
4940-11-8 \\
120-57-0 \\
121-33-5 \\
881-68-5\end{array}$ & $\begin{array}{l}140 \\
150 \\
152 \\
172 \\
208 \\
208 \\
210 \\
140 \\
150 \\
152 \\
194\end{array}$ \\
\hline
\end{tabular}

GC-MS, gas chromatography-mass spectrometry.

Table 3. Effect of Various Electronic Nicotine Delivery System Flavorings on InTERleukin-8 Release from Different Lung Cells IN Vitro

\begin{tabular}{|c|c|c|c|}
\hline $\begin{array}{l}\text { Flavoring } \\
\text { chemicals, concentrations } \\
(10 \mu M, 100 \mu M, 1 \mathrm{mM})\end{array}$ & $\begin{array}{c}\text { Human bronchial } \\
\text { epithelial cells (Beas } 2 B)\end{array}$ & $\begin{array}{c}\text { Human lung } \\
\text { fibroblasts (HFL-1) }\end{array}$ & $\begin{array}{c}\text { Human mucoepidermoid } \\
\text { carcinoma cells (H292-lung } \\
\text { epithelial cells) }\end{array}$ \\
\hline Acetoin & & & No change \\
\hline Pentanedione & No change & & No change \\
\hline Diacetyl & & No change & No change \\
\hline Ortho-vanillin (vanillin) & & & No change \\
\hline Maltol (malt) & & & Insignificant \\
\hline Cinnamaldehyde & No change & No change & No change \\
\hline Coumarin & No change & No change & No change \\
\hline
\end{tabular}

Different concentrations of flavoring chemicals/agents were used to treat three different lung cells, and IL- 8 levels were analyzed by ELISA. Arrows denote the extent of increased secretion of IL-8 as shown in Figures 1-3: low (one arrow), medium (two arrows), and high (three arrows).

ELISA, enzyme-linked immunosorbent assay; IL-8, interleukin-8. 

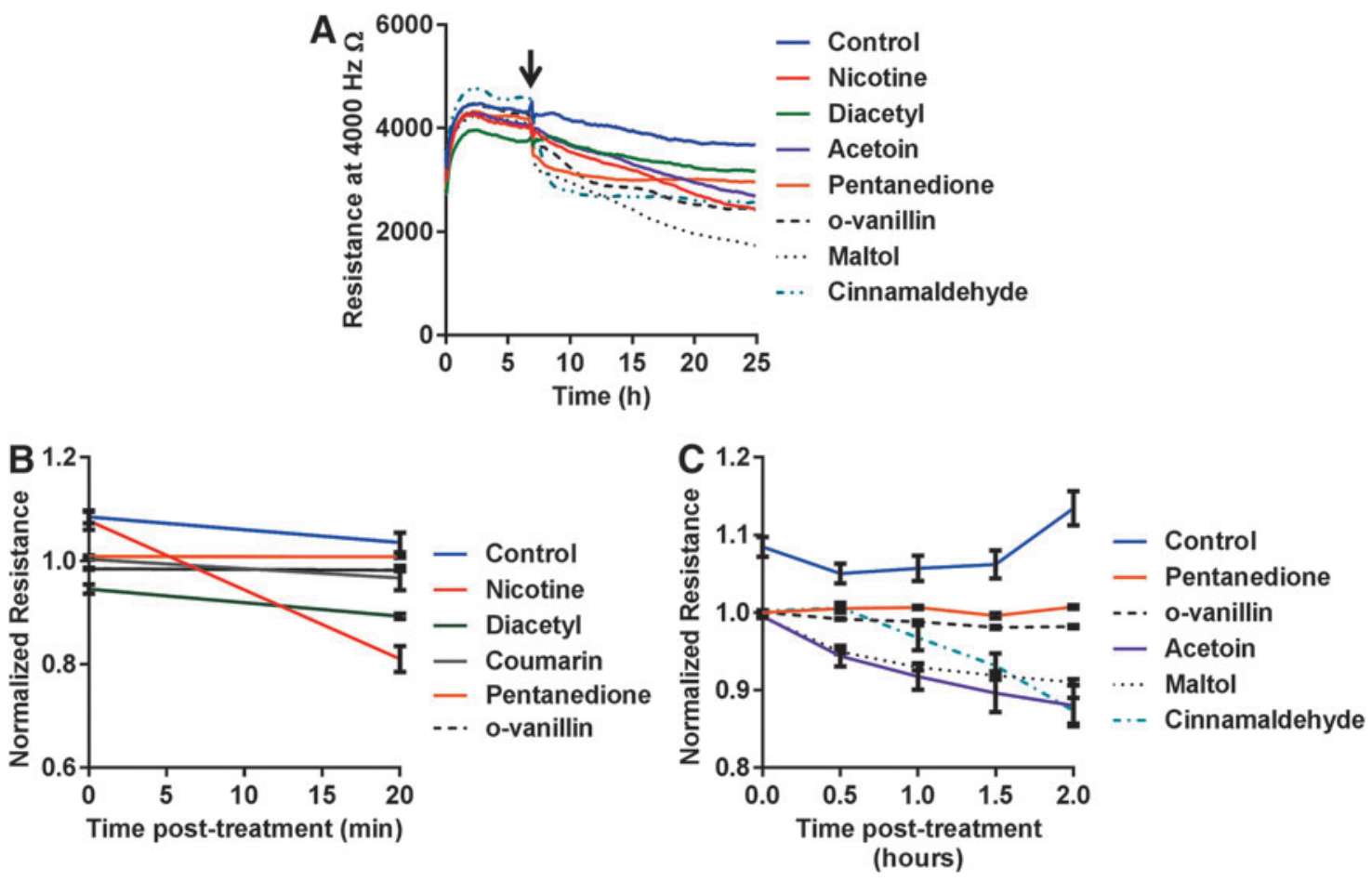

FIG. 4. Effects of nicotine and flavoring chemicals on electrical resistance in 16-HBE cells. 16-HBE cells were seeded in ECIS array/cultureware. Cells were grown for 2 days in complete medium with $10 \%$ FBS, then placed in medium containing low serum (1\% FBS) and treated with nicotine or different flavoring chemicals $(1 \mathrm{mM})$ and monitored for 16-24 hours. Resistance was measured at $4000 \mathrm{~Hz}$ using ECIS. (A) Representative data showing absolute resistance for control (no treatment), nicotine, and different flavoring chemicals. Black color arrow indicates the exact time of treatment. (B) Normalized resistance values for control, nicotine, and treatment with different flavoring chemicals ( 0 vs. 20 minutes post-treatment). $* * p<0.01$ coumarin versus control; ***p $<0.001$ diacetyl versus control. (C) Normalized resistance values for control and different flavoring chemicals 2 hours post-treatment. Statistical analysis of significance for normalized resistance values was compared between control vs. different flavoring chemicals at only 2-hour time point. Data are expressed as mean \pm SEM ( $n=6-8$ /group), and significance determined using two-way ANOVA (Sidak's multiple comparisons test). * $p<0.05$ cinnamaldehyde versus control; $* * * p<0.001$, acetoin and maltol versus control. ECIS, electric cell-surface impedance sensing; FBS, fetal bovine serum.

recently shown that e-cig flavors can be harmful to lung tissue by imposing oxidative stress both in vitro and in vivo. ${ }^{19,20}$ The potential inflammatory response by e-cig flavoring chemicals on human lung epithelial cells and fibroblasts is not known. In this study, we determined the secretion of the proinflammatory cytokine (IL-8 release) in response to different e-cig flavors/flavoring chemicals: acetoin (butter), pentanedione, diacetyl, maltol (malt), ortho-vanillin (vanilla), coumarin, and cinnamaldehyde in human bronchial epithelial cells (Beas2B), transformed lung epithelial cells (H292), and human lung fibroblasts (HFL-1). These chemicals and nontoxic concentrations tested were chosen based on our own data (Tables 1 and 2) and other studies. ${ }^{5-7,21}$

We found that the flavoring chemicals, such as acetoin, diacetyl, ortho-vanillin, and maltol, were more potent in eliciting an IL-8 response in Beas2B cells. HFL-1 cells treated with acetoin, pentanedione, ortho-vanillin, and maltol flavoring chemicals also showed a significant increase in IL-8 release. Of the seven different flavoring chemicals tested, two flavoring chemicals (acetoin in Beas2B cells and pentanedione in HFL-1 cells) showed an even more potent response to proinflammatory IL- 8 release compared to $\mathrm{TNF} \alpha$ treatment. IL-8 release in transformed lung epithelial cells (H292) was not induced by any of the seven different flavoring chemicals.
Cell viability was not affected by treatments with different doses of chemical flavorings. Barrier function is an important parameter for keeping the integrity of the TJs and intercellular contacts. Cigarette smoke has been shown to affect epithelial barrier function and cell-cell contact recovery. ${ }^{22}$ Several reports demonstrate the use of 16-HBE cells as a reliable in vitro model as they polarize and form functional adherens junctions and TJs under submerged culture conditions for studying epithelial barrier function. ${ }^{23-26}$ Previously, it has been shown that soluble components of e-cig, including nicotine exposure, caused a dose-dependent loss of lung endothelial barrier function associated with oxidative stress and inflammatory response. ${ }^{27}$ Our data show that nicotine and ecig flavoring agents (diacetyl, acetoin, coumarin, pentanedione, maltol, ortho-vanillin, and cinnamaldehyde) differentially affect epithelial barrier function time dependently. This suggests that both nicotine and flavoring chemicals in e-cigs are equally responsible for compromising epithelial integrity/TJ, which allows particles to cross the epithelial barrier. Further investigation is required to determine the exact mechanism as to how nicotine and e-cig flavoring chemicals induce disassembly of TJs and cause transient or persistent decrease in epithelial barrier function and thereby impairing the mucosal immune barrier and inflammatory response. 
Recent studies have highlighted the importance of research needed on high doses of flavoring chemicals, their potentially toxic degradation products, and specific flavoring chemicals present in e-cig e-liquids/refills as well as their consequences when inhaled. ${ }^{1,10,28,29}$ There are more than 8000 flavors for e-cigs on the market, such as chocolate, vanilla, coffee, and apple. ${ }^{1}$ These flavoring chemicals may pose a major and potential hazard in ENDS users when they are aerosolized into ultrafine particles reaching distal areas of the lungs. All of the food flavoring chemicals approved and evaluated as safe by FEMA for ingestion are now widely being used in ENDS without knowing their safety and inhalation toxicity. Flavoring chemicals, such as diacetyl $(2,3-$ butanedione), are commonly used in foods to provide buttery or creamy flavor. High doses of diacetyl flavoring when inhaled by factory workers have been reported to cause acute onset of bronchiolitis obliterans (a severe and irreversible obstructive lung disease) ${ }^{5,16}$ Bronchiolitis obliterans is inflammation of the bronchioles due to inhalation of chemical particles. ${ }^{16}$ The inflammation caused by an inhaled flavoring chemical can result in irreversible scarring that can damage lung epithelial cells and fibroblasts. We confirmed that the flavoring chemical diacetyl can cause damaging response in human lung epithelial cells (Beas2B). Our result on diacetyl significantly inducing the IL- 8 response suggests that the toxic response of e-cig flavorings may be due to the lung inflammatory response. We have shown that human lung epithelial cells and fibroblasts (HFL-1) release reactive oxygen species by e-cig flavoring agents. ${ }^{30}$

Furthermore, other flavoring chemicals, two of which are found in e-cig aerosols/e-liquids based on our emission GCMS data, such as acetoin, ortho-vanillin, and maltol, did also trigger the inflammatory response by release of IL-8 inflammatory cytokine in these cells (Beas2B and HFL-1). We found some additional chemicals from e-liquids using $\mathrm{GC}$ MS, such as nicotyrine, benzaldehyde, furanone, propylpyridine, pyrrole, and benzene derivatives, but we did not test these flavoring chemicals in cell culture models in this study.

The reasons for induction of proinflammatory response are not known, but it is possible that these agents could cause mitochondrial dysfunction and/or the release of $\operatorname{ROS}^{20}$ A prior study showed the comparison of 29 different flavored e-cig refill fluids and the cytotoxic response in cultured human embryonic stem cells (hESC), mouse neural stem cells (mNSC), and human pulmonary fibroblasts (hPF). ${ }^{15}$ Differential cytotoxic response was observed in hESC, mNSC, and hPF treated with flavored e-liquids. Cytotoxicity was not due to nicotine, but was correlated with the total number and concentration of chemicals present in different flavored eliquids. ${ }^{15}$ An interesting report demonstrates the effect of e-cig liquid flavorings on mediated cytotoxic response and activation of cystic fibrosis transmembrane conductance regulator ion channel by the chocolate flavoring chemical 2,5dimethylpyrazine in immortalized human bronchial epithelial cells $(16 \mathrm{HBE}){ }^{14}$

Oxidative stress would then activate $\mathrm{NF}-\kappa \mathrm{B}$ leading to the induction of NF- $\kappa$ B-mediated proinflammatory genes. Similar observations were noticed by others in terms of activation of inflammatory mediators by e-cig aerosols/e-liquids in vitro in cells. $^{31,32}$ The release of IL- 8 may attract/activate neutrophils by chemotaxis as evidenced recently by e-cig exposure. ${ }^{33}$ Our data showed increased IL- 8 secretion from epithelial cells (Beas2B) and fibroblasts (HFL-1), but did not show any significant increase in $\mathrm{H} 292$ transformed epithelial cells, although $\mathrm{TNF} \alpha$ (as positive control) had the expected effect. The reason for this different response is not known, but it may be highlighted that a similar response is seen in adenocarcinoma-transformed alveolar epithelial cells by cigarette smoke extract. ${ }^{34}$ This might be due to the shedding of some TLRs or sustained signaling cascades. Recently, it has been shown that ENDS aerosol containing flavorings on exposure in human bronchial epithelial cells caused decreased metabolic activity and viability, and increased release of cytokines, such as IL-1 $\beta$, IL-6, IL-10, CXCL1, CXCL2, and CXCL10. ${ }^{29}$ In the study mentioned above, GC-MS analysis identified flavoring chemicals such as 3-methylcyclopentane-1,2-dione (E)- $\beta$-damascone, allyl-cyclohexyl propionate, methyl 3hydroxyhexanoate, menthol, limonene, carvone, 5-methyl-2phenylhex-2-enal, benzyl alcohol, $\gamma$-decalactone, and methyl cinnamate. These chemicals are present in flavored ENDS, but the effects of these flavoring chemicals have not been tested on lung cells. Another report showed cherry-flavored e-cigs expose users to high levels of benzaldehyde (an aromatic aldehyde, inhalation irritant), and 30 puffs from flavored e-cigs contained higher levels of benzaldehyde than doses inhaled from conventional cigarettes. ${ }^{28}$ Recently, it has been shown that 16-HBE cells treated with subcytotoxic concentrations of 2,5-dimethylpyrazine, a chemical present in chocolate and nutty flavored e-cig (as low as $0.06 \% \mathrm{v} / \mathrm{v}$ and higher), caused distinct cellular impedance changes. This flavoring chemical 2,5-dimethylpyrazine with altered impedance also caused physiological response and dampened cellular signaling key in airway epithelial cell innate immunity. ${ }^{14}$ Our study is the first to demonstrate impaired airway epithelial barrier function by different e-cig flavoring chemicals at nontoxic concentration in 16-HBE cells using ECIS.

In a recent evaluation of flavored ENDS liquids, the presence of diacetyl and 2,3-pentanedione was found in 47 of 51 flavored e-liquids. ${ }^{5}$ It was also estimated that daily inhaled exposure to diacetyl $(47.3 \%)$ and 2,3-pentanedione $(41.5 \%)$ in e-cig users of $3 \mathrm{~mL} /$ day of ENDS e-liquid will exceed the National Institute of Occupational Safety and Health recommendation standards. ${ }^{8}$ Recently, the presence of $\sim 1 \%-$ $4 \%$ total flavoring chemicals $(10-40 \mathrm{mg} / \mathrm{mL})$ and major flavoring chemicals, which include aldehydes (primary irritant of mucosal tissue of the respiratory tract) along with other flavoring chemicals such as vanillin and/or ethyl vanillin, was identified in flavored e-liquids. ${ }^{10} \mathrm{We}$ have used some of the chemical flavorings reported recently in e-cig e-liquids/refills at different doses in this study and found differential responses to proinflammatory IL-8 release in lung cells. Epidemiological studies have clearly provided sufficient evidence that flavored e-cigs such as candy, fruit, and menthol appeal to adolescents compared to tobacco or alcohol flavored e-cigs. ${ }^{35,36}$ The harmful effects of e-cig aerosol/e-liquid inhaled flavorings need to be investigated. Our data demonstrate that flavoring chemicals present in e-liquids can cause epithelial barrier dysfunction in 16-HBE and proinflammatory response to a variety of widely used lung epithelial cell lines, which are surrogate for primary cells for research. It would be pertinent to examine the effects of flavoring chemicals, including volatile chemicals and aldehydes/carbonyls, on human primary lung epithelial cells, fibroblasts, and peripheral blood monocytes for inflammatory responses using 
an air-liquid interface system ${ }^{19,20}$ and primary cells from healthy subjects versus e-cig (flavorings) users. Further studies are required to determine flavoring agents/chemicals detected from various e-liquids and emissions using derivatization or collecting/injecting vapor phase via impinger or syringes or by increasing the puff duration/volume to 300 400 puffs based on human topography of e-cig vaping for vapor-phase emission. ${ }^{7,21}$

In conclusion, our findings suggest that flavoring chemicals are present in e-liquid/e-cig aerosols, which are proinflammatory and long-term exposure to flavoring chemicals may lead to lung injurious responses. The mechanistic inflammatory effects of e-cig flavorings on lung cells and tissue will provide a better understanding of how lung cells respond to specific ecig flavoring additives involved in impaired epithelial barrier function that might pose ensuing lung-damaging and pathological responses in e-cig users. This will possibly help to gauge the risk associated with these toxic flavoring agents, as these are approved for ingestion, but not for inhalation. Future studies by using novel in vitro and in vivo models will examine both the short- and long-term consequences of inhaled e-cig aerosols/e-liquid containing flavoring additives on lung and oral health.

\section{Acknowledgments}

The authors thank A. Gary DiFrancesco for collecting the ecig emissions and Morgan R. Bida and Cody Cummings for their help in sample preparation and GC-MS analysis. They are grateful to Dr. Arshad Rahman's laboratory for helping in conducting ECIS experiments. This study was supported by the NIH 2R01HL085613 and 3R01HL085613-07S2.

\section{Authors' Contributions}

J.G., R.F., I.K.S., E.R.S., A.E.F., T.P., R.R., and I.R.: Conceived and designed the experiments; J.G., R.F., I.K.S., E.R.S., A.E.F., and T.P.: Performed the experiments and analyzed the data; I.K.S. and I.R.: Wrote the manuscript.

\section{Author Disclosure Statement}

No competing financial interests exist.

\section{References}

1. Barrington-Trimis JL, Samet JM, McConnell R. Flavorings in electronic cigarettes: An unrecognized respiratory health hazard? JAMA 2014:312;2493-2494.

2. McMillen RC, Gottlieb MA, Shaefer RM, et al. Trends in electronic cigarette use among U.S. adults: Use is increasing in both smokers and nonsmokers. Nicotine Tob Res 2015: $17 ; 1195-1202$.

3. Feirman SP, Lock D, Cohen JE, et al. Flavored tobacco products in the United States: A systematic review assessing use and attitudes. Nicotine Tob Res 2016:18; 739-749.

4. Schoenborn CA, Gindi RM. Electronic cigarette use among adults: United States, 2014. NCHS Data Brief 2015:217;1-8.

5. Allen JG, Flanigan SS, LeBlanc M, et al. Flavoring chemicals in e-cigarettes: diacetyl, 2,3-pentanedione, and acetoin in a sample of 51 products, including fruit-, candy-, and cocktail-flavored e-cigarettes. Environ Health Perspect 2016: $124 ; 733-739$.

6. Cheng T. Chemical evaluation of electronic cigarettes. Tob Control 2014:23 Suppl 2;ii11-ii17.

7. Hutzler C, Paschke M, Kruschinski S, et al. Chemical hazards present in liquids and vapors of electronic cigarettes. Arch Toxicol 2014:88;1295-1308.

8. Farsalinos KE, Kistler KA, Gillman G, et al. Evaluation of electronic cigarette liquids and aerosol for the presence of selected inhalation toxins. Nicotine Tob Res 2015:17;168-174.

9. Lisko JG, Tran H, Stanfill SB, et al. Chemical composition and evaluation of nicotine, tobacco alkaloids, $\mathrm{pH}$, and selected flavors in e-cigarette cartridges and refill solutions. Nicotine Tob Res 2015:17;1270-1278.

10. Tierney PA, Karpinski CD, Brown JE, et al. Flavour chemicals in electronic cigarette fluids. Tob Control 2016:25;e10-e15.

11. Behar RZ, Davis B, Wang Y, et al. Identification of toxicants in cinnamon-flavored electronic cigarette refill fluids. Toxicol In Vitro 2014:28;198-208.

12. Zhu SH, Sun JY, Bonnevie E, et al. Four hundred and sixty brands of e-cigarettes and counting: Implications for product regulation. Tob Control 2014:23 Suppl 3;iii3-iii9.

13. Grana R, Benowitz N, Glantz SA. E-cigarettes: A scientific review. Circulation 2014:129;1972-1986.

14. Sherwood CL, Boitano S. Airway epithelial cell exposure to distinct e-cigarette liquid flavorings reveals toxicity thresholds and activation of CFTR by the chocolate flavoring 2,5dimethypyrazine. Respir Res 2016:17;57.

15. Bahl V, Lin S, Xu N, et al. Comparison of electronic cigarette refill fluid cytotoxicity using embryonic and adult models. Reprod Toxicol 2012:34;529-537.

16. Kreiss K. Flavoring-related bronchiolitis obliterans. Curr Opin Allergy Clin Immunol 2007:7;162-167.

17. Anderson JM, Van Itallie CM. Physiology and function of the tight junction. Cold Spring Harb Perspect Biol 2009: $1 ; \mathrm{a} 002584$.

18. Wegener J, Keese CR, Giaever I. Electric cell-substrate impedance sensing (ECIS) as a noninvasive means to monitor the kinetics of cell spreading to artificial surfaces. Exp Cell Res 2000:259;158-166.

19. Lerner CA, Sundar IK, Yao H, et al. Vapors produced by electronic cigarettes and e-juices with flavorings induce toxicity, oxidative stress, and inflammatory response in lung epithelial cells and in mouse lung. PLoS One 2015:10;e0116732.

20. Lerner CA, Rutagarama P, Ahmad T, et al. Electronic cigarette aerosols and copper nanoparticles induce mitochondrial stress and promote DNA fragmentation in lung fibroblasts. Biochem Biophys Res Commun 2016:477;620-625.

21. Kosmider L, Sobczak A, Fik M, et al. Carbonyl compounds in electronic cigarette vapors: Effects of nicotine solvent and battery output voltage. Nicotine Tob Res 2014:16;1319-1326.

22. Heijink IH, Brandenburg SM, Postma DS, et al. Cigarette smoke impairs airway epithelial barrier function and cellcell contact recovery. Eur Respir J 2012:39;419-428.

23. Hackett TL, de Bruin HG, Shaheen F, et al. Caveolin-1 controls airway epithelial barrier function. Implications for asthma. Am J Respir Cell Mol Biol 2013:49;662-671.

24. Heijink IH, Brandenburg SM, Noordhoek JA, et al. Characterisation of cell adhesion in airway epithelial cell types using electric cell-substrate impedance sensing. Eur Respir J 2010:35;894-903.

25. Heijink IH, Jonker MR, de Vries M, et al. Budesonide and fluticasone propionate differentially affect the airway epithelial barrier. Respir Res 2016:17;2. 
26. Ehrhardt C, Kneuer C, Fiegel J, et al. Influence of apical fluid volume on the development of functional intercellular junctions in the human epithelial cell line 16HBE14o-: Implications for the use of this cell line as an in vitro model for bronchial drug absorption studies. Cell Tissue Res 2002:308;391-400.

27. Schweitzer KS, Chen SX, Law S, et al. Endothelial disruptive proinflammatory effects of nicotine and e-cigarette vapor exposures. Am J Physiol Lung Cell Mol Physiol 2015:309;L175L187.

28. Kosmider L, Sobczak A, Prokopowicz A, et al. Cherryflavoured electronic cigarettes expose users to the inhalation irritant, benzaldehyde. Thorax 2016:71;376-377.

29. Leigh NJ, Lawton RI, Hershberger PA, et al. Flavourings significantly affect inhalation toxicity of aerosol generated from electronic nicotine delivery systems (ENDS). Tob Control 2016:25 Suppl 2:ii81-ii87.

30. Lerner CA, Sundar IK, Watson RM, et al. Environmental health hazards of e-cigarettes and their components: Oxidants and copper in e-cigarette aerosols. Environ Pollut 2015:198;100-107.

31. Hwang JH, Lyes M, Sladewski K, et al. Electronic cigarette inhalation alters innate immunity and airway cytokines while increasing the virulence of colonizing bacteria. J Mol Med (Berl) 2016:94;667-679.

32. Wu Q, Jiang D, Minor M, et al. Electronic cigarette liquid increases inflammation and virus infection in primary human airway epithelial cells. PLoS One 2014:9; e108342.
33. Higham A, Rattray NJ, Dewhurst JA, et al. Electronic cigarette exposure triggers neutrophil inflammatory responses. Respir Res 2016:17;56.

34. Moodie FM, Marwick JA, Anderson CS, et al. Oxidative stress and cigarette smoke alter chromatin remodeling but differentially regulate NF-kappaB activation and proinflammatory cytokine release in alveolar epithelial cells. FASEB J 2004:18;1897-1899.

35. Goldenson NI, Kirkpatrick MG, Barrington-Trimis JL, et al. Effects of sweet flavorings and nicotine on the appeal and sensory properties of e-cigarettes among young adult vapers: Application of a novel methodology. Drug Alcohol Depend 2016:168;176-180.

36. Pepper JK, Ribisl KM, Brewer NT. Adolescents' interest in trying flavoured e-cigarettes. Tob Control 2016:25 Suppl 2;ii62-ii66.

Address correspondence to:

Dr. Irfan Rahman

Department of Environmental Medicine University of Rochester Medical Center

Box 850

601 Elmwood Avenue Rochester, NY 14642

E-mail: irfan_rahman@urmc.rochester.edu 